\title{
The Relationship of Defensive Styles and Islamic Quality of Life With Death Obsession in Women With Breast Cancer
}

DOI: $10.30699 /$ acadpub.mci.4.1.15

\author{
Alireza Sangani ${ }^{1, ~ *, ~ N a h i d ~ R a m a k ~}{ }^{2}$, Leila Azizi ${ }^{3}$, Paria Jangi ${ }^{4}$ \\ ${ }^{1}$ Department of Psychology, Ahvaz Branch, Islamic Azad University, Ahwaz, Iran \\ ${ }^{2}$ Department of Psychology, Bandar Gaz Branch, Islamic Azad University, Ban- \\ dar Gaz, Iran \\ ${ }^{3}$ Department of Nursing, Gorgan Branch, Islamic Azad University, Gorgan, Iran \\ ${ }^{4}$ Department of Psychology, Science and Research Branch of Tehran, Islamic \\ Azad University, Tehran, Iran
}

*Corresponding author: Alireza Sangani,Department of Psychology, Ahvaz Branch, Islamic Azad University, Ahvaz, Khoozestan, Iran. Tel: +98-6133348420, Fax: +98-6133329200, E-mail: sangany.psycho@gmail.com

Submitted:11 October 2019

Revised: 28 October 2019

Accepted: 19 November 2019

e-Published: 1 January 2020

Keywords:

Defense Mechanisms

Quality of Life

Obsessive Behavior

Breast Neoplasms

Introduction: Breast cancer is one of the most common types of cancer in women with an increasing outbreak. The present study aimed to investigate the relationship between defensive styles and Islamic quality of life (QoL) with death obsession in women with breast cancer.

Methods: This research was a correlational study. The statistical population of the study included 220 female patients with breast cancer; referring to Cancer Patients Association of Gorgan in 2019. According to Krejcie and Morgan's table, 136 women were selected from breast cancer patients by simple random sampling. Islamic QoL questionnaire of Mohammad Namaqi et al., defense styles questionnaire of Andrews et al., and obsession with death questionnaire of Abdel-Khalek were applied. Data were analyzed; using the Kolmogorov-Smirnov test, Pearson correlation, and stepwise regression.

Results: The results showed that there was a negative significant relationship between the developed defensive style and the Islamic QoL with death obsession $(\mathrm{P}=0.001)$. There was a positive significant relationship between the neurotic and undeveloped defensive style with the death obsession $(\mathrm{P}=0.001)$. In addition, the results of the regression showed that the Islamic QoL (-0.257) and developed defensive style (-0.196) had the potential for predicting the obsession of death.

Conclusions: These results emphasize the necessity of the role defensive styles and Islamic QoL on the death obsession. So, therapists and counseling in the treatment of cancer for reducing obsession may benefit from paying attention to Islamic QoL and defensive styles.

C 2020. Multidisciplinary Cancer Investigation

\section{INTRODUCTION}

At the beginning of the $21^{\text {st }}$ century, cancers are one of the leading causes of death in the world. The incidence of breast cancer in women is increasing in developing countries due to changes in lifestyle and nutrition [1]. In addition, getting informed about this diagnosis can be very stressful for the patient both physically and psychologically [2], so that one of the feelings that they face after facing the cancer diagnosis is the feeling of being close to the death; taking on a form of obsession [3]. Nowadays, death obsession is described as one of the most important psychological components in patients with cancer [4]. According to the theory of panic management, the remembrance of mortality leads to the production of phenomenal anxiety by increasing the stressfulness of death thoughts [5]. Abdel-Khalek believes that 
there is an overlap between death and obsession [6]. Death is a possible subject in obsession [6] so that one can say about individual differences and defensive styles in the death obsession [7]. One can also talk about individual differences in death obsession, in other words, it can be said that some people are worried about death [8]. The results of the research showed that there were individual differences in the attitude and reaction to the phenomenon of death in natural or neurotic forms [9]. Although some defensive styles are normal and people use them more or less, they will lead to obsessive, frequent, and anxious if being used extremely [10]. Freud considers the defense as the result of a conflict between impulses and their satisfaction which has been hit by a serious inhibition [11]. Defenses are divided into undeveloped and developed neurotic categories [12]. The defensive undeveloped defense is considered to be regressive; while neurotic defenses are divided into obsessive and suppressive components [13]. Developed defensive mechanisms are considered to be adaptive, normal, and efficient methods of exposure [14]. On the other hand, the death obsession of this group of patients can affect their quality of life (QoL) [15]. Studies have also shown that religious beliefs and the quality of religious communications have a significant impact on the recovery process [16]. Javadi Amoli defines the quality of Islamic life as follows: the human development environment has to be in peace and health with his/her Lord, ego, congeners and with the environment surroundings himself/herself [17]. Therefore, the quality of Islamic life can be considered as a multidimensional construct in general. Objective or environmental aspect refers to meeting the social and cultural demands for material wealth, social base, and physical well-being and the subjective or psychological aspect refers to satisfaction feeling in general [18]. In fact, the subjective aspect of Islamic QoL includes spiritual perceptions and the individuals' values of their living conditions and describes the ways by which people percept and evaluate their surrounding [19]. The issue of spirituality and relationship with God, ourselves, other human being, and nature is one of the most pivotal aspects of this QoL which is less mentioned in other religions [20]. If human beings always rely on an entity in his/her perception that will always support them in all circumstances [21] and considers their interest, it will result in their satisfactory performance in all circumstances. This satisfaction is one of the basic aspects of the QoL, the one that comes within the relationship with the creator, not with the environment [22].

In this regard, the results of the study performed by Homayouni et al., shows that there is a relationship between Islamic lifestyle with death obsession in physical and mental aspects in people with cancer [23]. Perry et al., showed that there was a relationship between defensive mechanisms in women with breast cancer and anxiety as well as their death obsession [24]. Chen et al., showed that there was a relationship between the QoL in women with breast cancer with anxiety symptoms such as obsession and lack of satisfaction with life [2]. $\mathrm{Ng}$ et al., showed that there was a relationship between complying with spirituality and religiosity with anxiety and depression as well as death obsession symptoms in people with cancer [15].

There has been no research studying the relationship between these variables in these individuals. Furthermore, previous studies have indicated the effects of religious and spiritual dimensions in expediting the healing process of cancer patients, and in Iran, the Islamic QoL has a standard questionnaire. Having in mind the outbreak of breast cancer throughout the world, the constant fear of the disease that leads to death, and the role and importance of recognizing spiritual factors such as the Islamic QoL and fundamental cognitive factors such as defensive styles in predicting the death obsession of the women with breast cancer, the present research aimed to find any possible relationship between defense mechanisms and the quality of Islamic life with the death obsession of women with breast cancer.

\section{METHODS}

This research was a correlational study. The statistical population of this study included all 224 female cancer patients who referred to the Cancer Patients Association in Gorgan city. They had referred to the Center during a three-month period from May to June 2019 and were aged between 25 to 35 years old. According to Krejcie and Morgan's table at the significant level of 0.05 and the confidence level of $95 \%$ equal to 136 women from breast cancer patients who were selected by simple random sampling. In addition, collecting the information was conducted individually in the centers. The confounding variables included the cognitive specifications of 
individuals such as intelligence and talent as well as the social and economic status of individuals.

Inclusion criteria consisted of female patients with breast cancer, being under the treatment at the early stages of the disease, being in the age range of 30 to 50 years, being diagnosed with breast cancer during the last six months and a maximum of 1 year, lack of another concurrent disease affecting the diagnosis, lack of a significant psychological problem by the diagnosis of Association's psychiatrist according to the psychiatry records and based on DSM5 criteria. Exclusion criteria included incomplete completion of the questionnaire and patients' withdrawal. In the implementation process before the sampling, explanations were given about the purpose of the study and maintaining the confidentiality of the material and at the same time, informed consent was received from the patients. The subjects were assured that they could withdraw the research if they did not want to continue the collaboration and they were free and decision-maker in this case.

Data were analyzed; using descriptive statistics, mean and standard deviation, and inferential statistics, Kolmogorov-Smirnov test for normality and Pearson correlation to investigate the relationship and stepwise regression for predictive analysis. SPSS18 software was used for data analysis.

\section{Measurement Tool}

\section{Death Obsession Questionnaire}

It is developed by Abdel-Khalek with 15 items, and 5 choices on a Likert scale $(1=$ Not at all, $2=$ low, $3=$ medium, $4=$ much, $5=$ very much). There are three factors: death rumination (questions: 5, 7, 12, 3, 10, $4,8,9$ ), death domination (questions: $1,6,15,2$ ), and repetitive beliefs about the death (questions: $14,13,11)[6]$. Scores for death rumination, death domination, and repetitive beliefs about death ranges from 8 to 40,4 to 20 , and 3 to 15 , respectively. Also, the total score ranges from 15 to 75 . The construct and concurrent validity were confirmed by the developers and reliability was obtained by Cronbach's alpha for death rumination (0.84), death domination (0.82), and repetitive beliefs about the death (0.80) and the overall score (0.91). According to Mohammadzadeh, the reliability was obtained by Cronbach's alpha for death rumination (0.82), death domination (0.79), and repetitive beliefs about the death $(0.78)$ and the overall score $(0.86)$ [5]. The reliability was obtained for death ruminant $(0.76)$, death domination (0.80), repetitive beliefs about the death $(0.73)$, and the overall score $(0.82)$ by Cronbach's alpha in the present research.

\section{Defensive Styles Questionnaire}

It was designed by Andres et al., with 40 items [25]. It has got 9 choices on the Likert scale ( $1=$ strongly disagree, $2=$ disagree, $3=$ mildly disagree, $5=$ neutral, $7=$ mildly agree, $8=$ agree, $9=$ strongly agree). The defensive style has three undeveloped (questions: 1 to 24), developed (questions: 25 to 32 ), and neurotic (questions: 33 to 40 ) factors. Scores range for undeveloped, developed, and neurotic factors are as follows: 24 to 216,8 to 72 , and 8 to 72 , respectively. The construct and concurrent validity have been confirmed by the developers and the reliability was obtained by Cronbach's alpha for developed (0.87), undeveloped (0.89), and neurotic (0.83) factors. In Iran, Fathi Ashtiani et al., obtained the reliability by Cronbach's alpha for developed (0.84), undeveloped (0.88) and neurotic (0.85) factors [26]. The reliability was obtained by Cronbach's alpha for developed (0.80), undeveloped (0.86] and neurotic $(0.79)$ factors in the present research.

\section{Islamic Quality of Life Questionnaire}

This Islamic QoL questionnaire has been developed based on Ayatullah Javadi Amoli's books until 2009 by Mohammad Nejad Mohammad Namaqi et al., with 62 items [27]. It has got 5 choices on the Likert scale ( $1=$ Completely disagree, $2=$ disagree, $3=$ medium, $4=$ agree, $5=$ completely agree). It has four factors including others (questions: 1 to 14), God (questions: 15 to 26), self (questions: 27 to 45), nature (questions: 46 to 62 ). Scores range for others, God, self, and nature were 14 to 70,11 to 55,18 to 90 , and 16 to 80 , respectively. Also, the total score ranges from 62 to 310 . The construct and concurrent validity have been confirmed by the developers and the reliability was obtained by Cronbach's alpha method for others (0.79), God (0.76), self (0.81), nature $(0.72)$, and the overall score $(0.86)$. The reliability was obtained by Cronbach's alpha method for others (0.84), God (0.88), self (0.84), and nature $(0.85)$ in the present research.

\section{RESULTS}

Thirty-one people were aged 25-35 years-old and 105 people were at the age interval of 36-50 years. 
The educational level of the majority of patients was under diploma (Table 1).

Table 1: Distribution of Frequency and the Percentage of the Demographic Characteristics of Participants in the Research

\begin{tabular}{lr}
\hline Demographic Variabls & Number(\%) \\
\hline Age Group & \\
\hline $25-35$ years & $31(22.79)$ \\
\hline $36-50$ years & $105(77.20)$ \\
\hline Education & \\
\hline Under Diploma & $71(52.20)$ \\
\hline Diploma & $56(41.17)$ \\
\hline Bachelor & $9(6.61)$ \\
\hline
\end{tabular}

Initially, the data normalization was verified by the Kolmogorov-Smirnov test by studying the assumptions and the Pearson correlation analysis conditions have been observed.

The results contained in Table 2 show the descriptive statistics of center-orientation index and dispersion index including the mean and standard deviation, also the minimum score and the maximum score of the research variables (Table 2).

The results contained in Table 3 show the Pearson correlation matrix of defensive styles, Islamic QoL and death obsession. In addition, the results showed that there was a negative significant relationship between the developed defensive style and the subscales of Islamic QoL (God, others, self, and nature) with death obsession ( $\mathrm{P}=0.001)$. There was a positive and significant relationship between the neurotic and undeveloped defensive style with the death obsession $(\mathrm{P}=0.001)$ (Table 3$)$.

In accordance with Table 4, the variables (defensive styles undeveloped, developed, neurotic, and Islamic QoL) were entered into the regression equation to predict death obsession. Watson's camera test was used to determine the difference between the actual values and the values predicted by the regression model. equal to 1.963 obtained, this value was between 1 and 3, which indicates that the errors are independent and they don't affect the analysis. In addition, the non-linearity of the data was confirmed by the inflation and tolerance of variance test, merely Islamic QoL and the developed defensive style were able to enter the equation in the prediction of death obsession. The amount of the significant effect $(\mathrm{P}=$ 0.001 ) of the Islamic QoL was equal to -0.257 and the developed defensive style was equal to -0.196 . (Table 4).

\section{DISCUSSION}

The purpose of this study was to investigate the relationship of defensive styles and Islamic QoL with death obsession in women with breast cancer and these results are consistent with some findings of researchers such as Aziza et al., who found that the scope of the spiritual role of Muslims and their profound religious influences will cause the reduction of the death obsession and acceptance of their current conditions. Thoughts, fears, and emotions are related to the final event of life and beyond the normal state of life [28]. Perry et al., showed that there was a relationship between defensive mechanisms in women with breast cancer

Table 2: Descriptive Statistics of Defensive Styles, Islamic Quality of Life and Death Obsession

\begin{tabular}{lrcc}
\hline & Mean \pm SD & Minimum Score & Maximum Score \\
\hline Undeveloped & $126.03 \pm 10.85$ & 25 & 189 \\
Developed & $41.85 \pm 8.74$ & 8 & 64 \\
Neurotic & $48.06 \pm 13.86$ & 9 & 71 \\
God & $25.14 \pm 3.16$ & 13 & 48 \\
Others & $21.30 \pm 4.23$ & 17 & 67 \\
Self & $40.16 \pm 6.11$ & 18 & 81 \\
Nature & $29.19 \pm 9.03$ & 17 & 72 \\
Islamic Quality of Life & $187.14 \pm 15.25$ & 69 & 254 \\
Death Rumination & $23.03 \pm 5.48$ & 9 & 38 \\
Death Dommination & $9.42 \pm 2.19$ & 4 & 20 \\
Repetitive Beliefs About the Death & $7.24 \pm 4.06$ & 3 & 14 \\
Death Obsession & $51.48 \pm 8.89$ & 15 & 73 \\
\hline
\end{tabular}


Table 3: Pearson Correlation Matrix of Ddefensive Styles, Islamic Quality of Life, and Death Obsession

\begin{tabular}{|c|c|c|c|c|c|c|c|c|c|c|c|}
\hline & 1 & 2 & 3 & 4 & 5 & 6 & 7 & 8 & 9 & 10 & 11 \\
\hline Undeveloped & 1 & & & & & & & & & & \\
\hline Developed & $-0.46^{a}$ & 1 & & & & & & & & & \\
\hline Neurotic & $0.36^{\mathrm{a}}$ & $-0.51^{\mathrm{a}}$ & 1 & & & & & & & & \\
\hline God & $-0.19^{a}$ & $0.24^{\mathrm{a}}$ & $-0.20^{\mathrm{a}}$ & 1 & & & & & & & \\
\hline Others & $-0.18^{a}$ & $0.27^{\mathrm{a}}$ & $-0.21^{\mathrm{a}}$ & $0.46^{\mathrm{a}}$ & 1 & & & & & & \\
\hline Self & $-0.20^{\mathrm{a}}$ & $0.21^{\mathrm{a}}$ & $-0.24^{\mathrm{a}}$ & $0.42^{\mathrm{a}}$ & $0.58^{\mathrm{a}}$ & 1 & & & & & \\
\hline Nature & $-0.23^{\mathrm{a}}$ & $0.18^{\mathrm{a}}$ & $-0.28^{a}$ & $0.49^{\mathrm{a}}$ & $0.34^{\mathrm{a}}$ & $0.31^{\mathrm{a}}$ & 1 & & & & \\
\hline Islamic Quality of Life & $-0.30^{\mathrm{a}}$ & $0.24^{\mathrm{a}}$ & $-0.29^{a}$ & $0.71^{\mathrm{a}}$ & $0.79^{\mathrm{a}}$ & $0.59^{\mathrm{a}}$ & $0.46^{\mathrm{a}}$ & 1 & & & \\
\hline Death Rumination & $0.22^{\mathrm{a}}$ & $-0.19^{a}$ & $0.1^{\mathrm{b}}$ & $-0.18^{\mathrm{a}}$ & $-0.20^{\mathrm{a}}$ & $-0.21^{\mathrm{a}}$ & $-0.24^{\mathrm{a}}$ & $-0.36^{\mathrm{a}}$ & 1 & & \\
\hline Death Domination & $0.20^{\mathrm{a}}$ & $-0.27^{\mathrm{a}}$ & 0.15 & $-0.27^{\mathrm{a}}$ & $-0.29^{\mathrm{a}}$ & $-0.17^{\mathrm{a}}$ & $-0.20^{\mathrm{a}}$ & $-0.29^{\mathrm{a}}$ & $0.48^{\mathrm{a}}$ & 1 & \\
\hline Repetitive Beliefs About the Death & $0.19^{\mathrm{a}}$ & $-0.30^{\mathrm{a}}$ & $0.13^{\mathrm{b}}$ & $-0.28^{\mathrm{a}}$ & $-0.20^{\mathrm{a}}$ & $-0.24^{\mathrm{a}}$ & $-0.26^{\mathrm{a}}$ & $-0.31^{\mathrm{a}}$ & $0.53^{\mathrm{a}}$ & $0.52^{\mathrm{a}}$ & 1 \\
\hline Death Obsession & $0.27^{\mathrm{a}}$ & $-0.31^{\mathrm{a}}$ & $0.24^{\mathrm{a}}$ & $0.30^{\mathrm{a}}$ & $0.21^{\mathrm{a}}$ & $0.19^{\mathrm{a}}$ & $0.26^{\mathrm{a}}$ & $0.32^{\mathrm{a}}$ & $0.70^{\mathrm{a}}$ & $0.66^{\mathrm{a}}$ & $0.69^{\mathrm{a}}$ \\
\hline
\end{tabular}

${ }^{a}$ Significant at the 0.05 level

${ }^{\mathrm{b}}$ Significant at the 0.01 level

Table 4: Stepwise Regression in Predicting Death Obsession With Defensive Styles and Islamic Quality of Life

\begin{tabular}{lcccccc}
\hline Steps & Predictor Variables & $\mathbf{R}^{2}$ Determination Coefficient & Effect Extent $[\boldsymbol{\beta}]$ & Estimation Error & $\mathbf{F}$ & $\mathbf{P}$ Value \\
\hline $\mathbf{1}$ & Islamic quality of life & 0.301 & -0.275 & 12.452 & 6.984 & 0.001 \\
$\mathbf{2}$ & Developed & 0.269 & -0.196 & 10.069 & 5.746 & 0.001 \\
\hline
\end{tabular}

with their anxiety and death obsession [24]. $\mathrm{Ng}$ et al., showed that there was a relationship between complying with spirituality and religiosity with anxiety and depression, as well as death obsession symptoms in people with cancer [15]. Homayouni et al., showed that there was a relationship between Islamic lifestyle with death obsession in physical and mental aspects in people with cancer [23]. Chen et al., showed that there is a relationship between QoL in women with breast cancer with anxiety symptoms such as obsession and lack of satisfaction with life [2]. In sum, the findings of past researches are consistent with the results of this study on the negative relationship between subscales of God, self, others, and nature of the variable of Islamic QoL and the developed defensive style with the death obsession, as well as the positive relationship between the undeveloped and the neurotic defensive style with the death obsession. The results of this study are consistent with previous studies do to the fact that the study population of both investigations are cancer patients. Also, in terms of the number of samples and sampling methods, were consistent with the present study. It confirms the results of previous research. Accordingly, based on the evolutionary viewpoint, one of the most important responses of the human beings and, in general, organisms, with regard to their conditions, will be emotional reactions based on neurotic and undeveloped defensive mechanisms, the reactions that are needed to preserve the organism's early survival [10]. Emotional responses based on neurotic and undeveloped defensive mechanisms relative to cancer include severe depression, sadness, and unhappiness, lack of control, change in personality, anger, and anxiety of death which will cause the creation of obsession if they are paid attention extremely [3]. Death obsession, which is rooted in the awareness of death and is considered as a negative reaction, is also a natural phenomenon that is influenced by social and cultural events and attitudes of people living in spiritual and religious areas.

On the other hand, spirituality is considered one of the basic principles based on the latest definitions of general health [15]. It is considered as one of the important aspects of health in humans which provides a coherent and integrated connection 
between the internal forces and is characterized by stability in life, peace, fit, and harmony, a sense of close relationship with the persons ego, God, society, and environment that are also among the aspects of the QoL [6]. In the quality of Islamic life, the relationship with God, self, others, and naturally leads to a better understanding of living conditions [18]. This enables the person to become more aware of their abilities and to be more resilient to problems such as illness and thus to experience less psychological vulnerability such as obsession [19]. The experience of living with cancer is evident that spiritual health is an important and prominent aspect of a healthy life and leads to a meaningful and targeted life in these patients. If the patient knows the purpose of his/her life, then he/ she can get along with what he or she thinks about "what and how" within his/her mind. The purpose of the person's life is part of his/her existential goal, which is obtained from his/her own life, and this part, in turn, constitutes the spiritual aspect of one's life. Nelson et al., showed that high levels of spiritual health are associated with low levels of the variables; related to psychological disorders such as depression, hopelessness and suicidal thoughts in patients with cancer [29]. In explaining the results obtained, it can be expressed that the defensive styles have attracted particular clinical and research attention due to the special importance in the conceptualization of psychological disorders and their treatment from psychoanalytical viewpoint and each mental disorder accompanies clear non-adaptive defenses and defensive styles in psychoanalysis system and plays an important role in the mental health of the individuals [9]. Neurotic and undeveloped defensive styles, in fact, distort the reality in people with death obsession thoughts, and the degree of the reality distortion in psychologically sad and undeveloped defenses is more than the developed ones. In another explanation based on the cognitive perspective, the more cognitive distortions of an event, situation, and even behavior, the less the level of conscious awareness thereupon, and consequently, less effort is made to deal with cognitive distortion [13]. Consequently, during a false period, the psychologically sad and undeveloped defensive styles increase and consequently, the obsession with the death and life phenomenons greatly increases
[11]. Therefore, the defensive styles in the course of the cancer disease, which are undeveloped, change the ego's conscious awareness, reduce the awareness of our conflicts and affect the feelings contradicting beliefs. Therefore, the defensive styles, especially the ones that are undeveloped more, become obstacles to understand the reality in a person [10] and deprive him/her of the possibility to a rational and effective defense and reduce the person's insight and self-exploration capacity, and the individual always uses the psychologically regressive styles to reduce the anxiety in death obsession.

Among the limitations of this research, we can point out to its gender restriction, breast cancer, restricted location, the short duration of the study, and lack of causation in the correlation method. Another limitation of the research was using the questionnaire tool; while using different evaluation methods such as interviewing and observing the results was more accurate. The results showed that there was a relationship between the defensive styles and Islamic life quality subscales (God, others, self, and nature) with death obsession. In addition, the regression results showed that the Islamic QoL and developed defensive styles have the potential to predict the death obsession. These results emphasize the necessity of the role of cognitive aspects defensive styles and Islamic QoL on the obsession and the attitude towards death. Therefore, it is recommended to therapists in the field of health to simultaneously pay attention to the psychological and spiritual therapies with regard to the basic mental structures such as defensive styles and Islamic QoL in addition to medication. It is also recommended to other researchers to conduct model studies with the mediating role of Islamic QoL in relation to defense styles with death obsession.

\section{ACKNOWLEDGMENTS}

This research could not be conducted without the collaboration of management, treatment centers for special diseases in order to achieve the samples of the studied subjects. All these loved ones are highly appreciated and acknowledged.

\section{CONFLICT OF INTEREST}

The authors did not have any conflicts of interest with any organization. 


\section{ETHICS APPROVAL}

All moral conditions including maintaining confidentiality, receiving informed consent and complying with respect have been carried out. In addition, this research has been registered with the ethics code of IR.IAU.AK.REC.1398.042 at the Azad University of Gorgan.

\section{REFERENCES}

1. Pan Y, Yang K, Wang Y, Zhang L, Liang H. Could yoga practice improve treatment-related side effects and quality of life for women with breast cancer? A systematic review and meta-analysis. Asia Pac J Clin Oncol. 2017;13(2):e79-e95. DOI: 10.1111/ajco.12329 PMID: 25560636.

2. Cheng K, Wong W, Koh C. Unmet needs mediate the relationship between symptoms and quality of life in breast cancer survivors. Support Care Cancer. 2016;24(5):202533. DOI: 10.1007/s00520-015-2994-0 PMID: 26530229.

3. Destri GL, Di Carlo I, Scilletta R, Scilletta B, Puleo S. Colorectal cancer and lymph nodes: the obsession with the number 12. World J Gastroenterol. 2014;20(8):1951. DOI: 10.3748/wjg.v20.i8.1951 PMID: 24587671.

4. Dolan R-D, McSorley S-T, Horgan P-G, McMillan D-C. Determinants of lymph node count and positivity in patients undergoing surgery for colon cancer. Medicine. 2018;97(13):e0185. DOI: 10.1097/ MD.0000000000010185 PMID: 29595652.

5. Mohammadzadeh A, Asgharnejad farid A-A, Ashouri A. The Study of Factor Structure, Validity and Reliability of the Death Obsession Scale (DOS). Adv Cogn Sci. 2009;11(1):1-7.

6. Abdel-Khalek A-M. The structure and measurement of death obsession. Pers Individ Dif. 1998;24(2):159-65. DOI: $\quad$ 10.1016/S0191-8869(97)00144-X.

7. Dadfar M, Lester D. Death concern and death obsession in Iranian nurses. Psychol Rep. 2015;116(3):704-9. DOI: 10.2466/12.13.PR0.116k30w5 PMID: 26030202.

8. Shakila Z, Yousafa T. Gender Differences in Death Obsession. Procedia Soc Behav Sci. 2015;185:146-50. DOI: 10.1016/j.sbspro.2015.03.414.

9. Kane AC, Hogan JD. Death anxiety in physicians: Defensive style, medical specialty, and exposure to death. OMEGA-J Death Dying. 1986;16(1):11-22. DOI: 10.2190/ TFG3-YQJQ-E0M6-4JYJ.

10. Di Giuseppe M, Ciacchini R, Micheloni T, Bertolucci I, Marchi L, Conversano C. Defense mechanisms in cancer patients: A systematic review. J Psychosom Res. 2018;115:76-86. DOI: 10.1016/i.jpsychores.2018.10.016 PMID: 30470322.

11. Harris V-K, Schiffman J-D, Boddy A-M. Evolution of cancer defense mechanisms across species. Ecol Evol Cancer: Elsevier; 2017. p. 99-110. DOI: 10.1016/B978-0-12804310-3.00007-7.

12. Garg A-D, Agostinis P. Cell death and immunity in cancer: from danger signals to mimicry of pathogen defense responses. Immunol Rev. 2017;280(1):126-48. DOI: 10.1111/imr.12574 PMID: 29027218.

13. Yang Y, Deng Y, Chen X, Zhang J, Chen Y, Li H, et al. Inhibition of PDGFR by CP-673451 induces apoptosis and increases cisplatin cytotoxicity in NSCLC cells via inhibiting the Nrf2-mediated defense mechanism. Toxicol Lett. 2018;295:88-98. DOI: 10.1016/j.toxlet.2018.05.033 PMID: 29857117.

14. Igaz I, Igaz P. Why is microRNA action tissue specific? A putative defense mechanism against growth disorders, tumor development or progression mediated by circulating microRNA? Med Hypotheses. 2015;85(5):530-3. DOI: 10.1016/j.mehy.2015.07.013 PMID: 26198739.

15. Ng GC, Mohamed S, Sulaiman AH, Zainal NZ. Anxiety and depression in cancer patients: the association with religiosity and religious coping. J Relig Health. 2017;56(2):57590. DOI: 10.1007/s10943-016-0267-y PMID: 27287259.

16. Javadi Amoli A. Tasnim: Commentary of the Noble Quran. Eslami A, editor. Qom: Asra; 2010.

17. Bahrami N, Moradi M, Soleimani M, Kalantari Z, Hosseini F. Death anxiety and its relationship with quality of life in women with cancer. Iran J Nurs. 2013;26(82):51-61.

18. Mohammadi P. Role of Teaching Religious-Psychological Teachings on the Quality of Life and Life Style of Islamic Azad University Students of Urmia. Islam Life J. 2018;3(1):37-42.

19. Alagheband M, Mazloomy-Mahmoodabad S-S, Yassini-Ardekani S-M, Fallahzadeh H, Rezaeib M-R, Yavari $\mathrm{M}-\mathrm{R}$, et al. Construction and validation of the Urban Quality of Life Scale with Islamic dimensions among Iranians. Ment Health Relig Cult. 2018;21(9-10):855-66. DOI: 10.1080/13674676.2018.1455654.

20. Moazedi K, Porzoor P, Pirani Z, Adl H, Ahmadi H. The effectiveness of Islamic teaching based religious-spiritual psychotherapy on quality of life, in infertile women. J Health. 2019;9(5):589-98. DOI: 10.29252/j.health.9.5.589.

21. Estes R-J, Sirgy M-J. Radical Islamic militancy and acts of terrorism: A quality-of-life analysis. Soc Indic Res. 2014;117(2):615-52. DOI: 10.1007/s11205-013-0363-2.

22. Celasin H, Karakoyun R, Yilmaz S, Elhan A, Erkek B, Kuzu M. Quality of life measures in Islamic rectal carcinoma patients receiving counselling. Colorectal Dis. 2011;13(7):e170-e5. DOI: 10.1111/j.14631318.2011.02649.x PMID: 21651692.

23. Homayouni A, Nikpour GA, M. S, editors. The Role of Quality of Islamic Life in Death obsessions of Cancer Patients. Second National Conference on Psychology and Consultation; 2017; Isfahan: Hasht Behesht University of Isfahan.

24. Perry JC, Metzger J, Sigal J-J. Defensive functioning among women with breast cancer and matched community controls. Psychiatry. 2015;78(2):156-69.

25. Andrews G, Singh M, Bond M. The Defense Style Questionnaire. J Nerv Ment Dis. 1993;181(4):246-56. DOI: 10.1097/00005053-199304000-00006 PMID: 8473876.

26. Afzali MH, Fathi-Ashtiani A, Azad Falah P. Comparison of Defense Styles \& Defense Mechanisms of Patients with 
Obsessive-Compulsive Disorder \& Normal People. J Behav Sci. 2008;2(3):245-52.

27. Nejadmohammad Namghi A, Borjali A, Esmaeeli M, Shafeabadi E, Bagheri F. Construction and Validation of Quality of Life Questionnaire Based on Ayatollah Javadi Amoli’s Views. J Psychol Models Methods. 2015;6(20):103-13.

28. Azaiza F, Ron P, Shoham M, Gigini I. Death and dying anx- iety among elderly Arab Muslims in Israel. Death Studies. 2010;34(4):351-64. DOI: 10.1080/07481181003613941 PMID: 24479192.

29. Nelson C-J, Rosenfeld B, Breitbart W, Galietta M. Spirituality, religion, and depression in the terminally ill. Psychosomatics. 2002;43(3):213-20. DOI: 10.1176/appi. psy.43.3.213 PMID: 12075036. 